Working

Paper

Department

of Economics

$\mathrm{Ca}^{\prime}$ Foscari University of

Venice

Paul Cheshire

Stefano Magrini

Raising urban productivity

or attracting people?

Different causes, different

consequences 


\title{
Raising urban productivity or attracting people? Different causes, different consequences
}

\author{
Paul Cheshire \\ London School of Economics \\ Stefano Magrini \\ University of Venice
}

\begin{abstract}
This paper investigates growth differences in the urban system of the EU12 over the last decades of the 20th Century. Models in which growth of real GDP p.c. and rates of population growth are the dependent variables are compared. This suggests that it makes sense to model GDP growth in a European context. The analysis supports the conclusion that systems of urban governance are significantly related to economic growth, as is the distribution of highly skilled human capital and R\&D activity. In addition, evidence is found supporting the conclusion that integration shocks in the EU favour core areas but when all else is controlled for peripheral regions experienced a systematic positive growth differential. Careful testing for spatial dependence reveals that national borders are significant barriers to adjustment but we can resolve such problems by including a set of variables designed to reflect spatial economic adjustment mechanisms where cities are densely packed so their economies interact. Models of population growth show some similar results but interesting and revealing differences. Strong evidence is found that there are substantial national border effects impeding the emergence of a full spatial equilibrium across the EU's urban system. Better climate is the single most significant variable but only when expressed relative to the national (not EU) mean. As with economic growth, there are significant national border effects in patterns of spatial dependence. Concentrations of human capital and R\&D, however are if anything negatively associated with attracting population - a finding which parallels the finding that a better climate relative to the national mean is associated with slower rather than faster growth of real GDP per capita.
\end{abstract}

\section{Keywords}

growth; cities; local public goods; human capital; convergence; territorial competition

JEL Codes

H41; H73; O18; R11; R50

\author{
Address for correspondence: \\ Stefano Magrini \\ Department of Economics \\ Ca' Foscari University of Venice \\ Cannaregio 873, Fondamenta S.Giobbe \\ 30121 Venezia - Italy \\ Phone: (++39) 0412349194 \\ Fax: (++39) 0412349176 \\ e-mail: smagrini@unive.it
}

This Working Paper is published under the auspices of the Department of Economics of the Ca' Foscari University of Venice. Opinions expressed herein are those of the authors and not those of the Department. The Working Paper series is designed to divulge preliminary or incomplete work, circulated to favour discussion and comments. Citation of this paper should consider its provisional character.

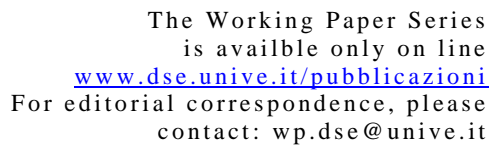

The Working Paper Series

is availble only on line www.dse.unive.it/pubblicazioni For editorial correspondence, please contact:wp.dse@unive.it

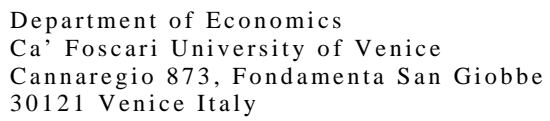

Department of Economics

Ca' Foscari University of Venice

Cannaregio 873, Fondamenta San Giobbe

30121 Venice Italy

Fax: ++390412349210 


\section{Introduction ${ }^{1}$}

We start with a brief analysis of demographic growth in the major city regions of the EU of 12 over the period 1980 to 2000 . This concludes that interregional migration is orders of magnitude less in the EU than in the US and responds to variables measuring quality of life only as they differ within countries. This suggests that it is appropriate to analyse differential rates of growth of real GDP per capita not just if one is interested in productivity growth differentials but also if one is interested in investigating differences in welfare changes across Europe's cities. Despite a compensating variations approach showing that people adjusted to differences in quality of life between cities within countries, the evidence strongly supports the conclusion that no such pattern exists across the urban system of Europe as a whole. In that sense, city regions within the EU seem to behave like city-states, not as simply the spatial units from which a continental economy is constructed. The central assumption of perfectly mobile factors and the equalisation of real marginal returns across cities explicit in models of compensating variations (the Quality of Life approach developed on the basis of Roback's 1982 contribution) cannot reasonably be maintained in the European context.

This paper, therefore, turns to an analysis of differential rates of growth of real income across city regions (represented as Functional Urban Regions or FURs - as used in Cheshire and Magrini, 2000). In particular, we explore the role of three types of variable identified in economic theory as potentially important in explaining economic growth in a spatial context. The first is the systematic spatial effects of European integration. Empirical interest in this goes back at least to Clark et al (1969) and it is interesting to use as an explanatory variable the measure actually derived by Clark and his associates before the impact of European integration was significantly felt. Interest in these factors has been given a significant boost as a result of the theoretical developments of New

\footnotetext{
1 The authors have benefited from many discussions with colleagues as this work has developed but remain responsible for any remaining deficiencies or errors.
} 
Economic Geography as summarised, for example, in Fujita et al., 1999. The second variable we are interested in is the role of R\&D and highly skilled human capital. Here we focus on testing a spatialised adaptation of endogenous growth theory (see Cheshire and Carbonaro, 1996 or, for a more rigorous development, Magrini, 1998). The third idea we are interested in investigating is the relationship between systems of city government and city growth performance. Here we test one of the basic propositions of fiscal federalism: that "the existence and magnitude of spillover effects clearly depends on the geographical extent of the relevant jurisdiction" (Oates, 1999). Specifically we test that there is a positive relationship between the degree of co-incidence of governmental boundaries with those of the functionally defined city-region and the growth performance of the city-region.

We have also pay particular attention to issues of spatial dependence. Spatial econometrics tends to exist as a distinct field in which a finding of spatial dependence is often an end in itself - sometimes to be 'corrected' by introducing spatial lags or other appropriate econometric devices. Our views are somewhat different. It seems important to test for spatial dependence since, if it is present, and the analysis does not properly take it into account, parameter estimates can be biased just as they can be in time series analysis if there are problems of serial autocorrelation which are not offset for. However, it seems to us that the discovery of spatial dependence should trigger a further but economically inspired investigation. An indicated problem of spatial dependence suggests there is a specification problem. Something which explains this pattern has been omitted and if the model is specified better then the problem should be resolved. This is particularly relevant in investigating spatial economic processes since theory suggests that there are important spatial adjustment mechanisms and other spatially determined features of economies. For example, labour markets and housing markets are likely to adjust to price and real wage differences in ways conditioned on some measure of distance. Theoretical and empirical investigations of agglomeration economies, human capital and innovation suggest there are important spatial 
aspects of these features of economies. These are possible sources of spatial interaction between cities' economies which, if not represented in the model, would plausibly show up as spatial dependence.

As the results reported below suggest, there seems to be some validity to this viewpoint. When we estimate growth models in which no spatial adjustment processes are explicitly included, tests show that there are problems of spatial dependence. However deliberately including measures of spatial economic adjustment processes, which are a function of the distance between cities, eliminates spatial dependence and specification problems.

In addition, the way in which the sensitivity of the models to measures of spatial dependence varies with the particular distance weights used to calculate 'proximity' (the spatial weights matrix) provides, in our interpretation, insight into economic processes. In processes of both population and GDP growth problems of spatial dependence only reveal themselves if an additional distance penalty to adjustment is included for national borders: this, we judge, tells one about the extent to which urban systems in Western Europe still interact as a set of national urban systems rather than as a unified EU urban system.

\section{Data and variables}

All the analysis is performed on a data set built up over a 25 year period relating to Functional Urban Regions (FURs) defined ${ }^{2}$ so far as possible according to common criteria across the EU of 12. Such FURs correspond to

\footnotetext{
2 For a detailed discussion of the definition of the FURs used throughout this paper see Cheshire and Hay (1989). They are defined on the basis of core cities identified by concentrations of employment and hinterlands from which more commuters flow to the employment core than to any other subject to a minimum cut off. They were defined on the basis of data for 1971. They are broadly similar in concept to the (Standard) Metropolitan Statistical Areas used in the US. As has been argued elsewhere (Cheshire and Hay, 1989) the great variability in the relationship between administrative boundaries and the economic reality of European cities and regions introduces serious error and a strong likelihood of bias into data reported for administratively defined cities. The FUR/city and region of Bremen provide an extreme but not wholly unrepresentative example. Because of population relative to employment decentralisation over the relevant period the growth of GDP p.c. is overstated by some $40 \%$ if the published Eurostat data for the administrative region is relied on.
} 
the economic spheres of influence of significant employment concentrations and are relatively self-contained in economic terms. The analysis is conducted only for FURs with a population of more than one third of a million and a core city which exceeded 200000 at some date between 1951 and 1981. Cities of the former eastern Länder of Germany and Berlin have to be excluded because of lack of data. The new basis on which Eurostat estimated regional GDP from 1995 onwards means that the analysis stops then. The variables used are defined in Table 1 which also provides a brief description of the sources used. More detail can be found in Cheshire and Magrini (2006b). All data are defined to common statistical concepts either weighting data available from the Eurostat REGIO database to estimate values for FURs or collected directly from national statistical offices or common data providers and adjusted where necessary to common definitions. There is necessarily some imperfection and imprecision in such data but they have the merit of not only allowing analysis of specifically European cities but also of allowing the investigation of questions which, because of lack of variation, simply could not be investigated in the context of the US urban system.

The analysis employs OLS but we provide substantial testing to see whether the results are subject to econometric problems. Since the observations represent the population of West European city-regions, the force of the standard objections to the use of cross sectional OLS for inference seem to be substantially mitigated. Compared to cross country 'growth regressions' our observations represent a relatively homogeneous population and data are more comparable. We also try to minimise the impact of the standard problems associated with the use of regression to investigate causal processes by using spatial units which minimise nuisance noise in the data and formulating variables in ways which reflect views of causal mechanisms and minimise problems of endogeneity. As with all applied econometrics, however, in the end the credibility of results is not a categorical issue but depends on judgement. Do the inevitable compromises forced on researchers mean that the 
departure from the ideal conditions is so great that the results are spurious for purposes of inference?

We have still not managed to find a satisfactory way of bridging the Eurostat regional GDP series across the difference in estimation methodology introduced in 1995 so our GDP series ends at 1994. Our dependent variable is estimated from common PPS values of GDP p.c. for Eurostat Level 3 regions. Estimates of GDP p.c. for FURs are derived by using the distribution of FUR population between Level 3 regions at the closest Census dates as weights and then applying those weights to the relevant Level 3 GDP p.c. data ${ }^{3}$. Because of measurement error and short run fluctuations in Eurostat data, we take the start point of the series as the mean for 1978-80 and the end point as the mean for 1992 to 1994 . We are thus analysing a period too short to correspond to a conceptual long run. Even if the system did tend to equalisation of returns to factors on the margin, new shocks and disturbances will occur long before such a position is reached. We need, therefore, to model a system in which real incomes can permanently (in the sense of any period we can observe) vary between cities.

The data used are derived mainly from Eurostat. Regional GDP data have been published for most Level 1, 2 and 3 regions since 1978 although for some they are available from 1977. There are, however gaps - data for Greek and Portuguese regions, for example, only became available later. In both cases, Eurostat data have been supplemented with national data. For some countries, such as Italy, Eurostat data for earlier years were only published for Level 2 regions. In this instance, national sources for value added have been used to disaggregate from Level 2 to Level 3 values. The climate data are taken from the Climate Research Unit (University of East Anglia) database and for each

\footnotetext{
${ }^{3}$ The EU institutions deal in so-called Nomenclature des Unités Territoriales Statistiques (N.U.T.S.) regions. This is a nesting set of regions based on national territorial divisions. The largest are Level 1 regions; the smallest for which a reasonable range of data is available are Level 3. These correspond to Counties in the UK, Départements in France; Provincies in Italy or Kreise in Germany. Because of cross border commuting flows there is inevitably built-in spatial nuisance dependence with this series. The use of self-contained FURs minimises this problem.
} 
city relate to the $30 \mathrm{~km}$ square which contains the geographical centroid of the FUR. In the case of Portsmouth and Southampton, the FURs fall within the same square but there is considerable climatic variation within most countries. Even within the Randstat cities of the Netherlands there is a 10 percent variation on most climate measures.

The same control variables are used for industrial structure as have been used in previous work (see Cheshire and Magrini, 2000, for an explanation and justification). As before, the more detailed measures relating to old resourcebased industries tend to work better than broader measures of specialisation in industry. However, it has been found that in most of the present models in which GDP p.c. is the dependent variable, the unemployment rate at the start of the period is a useful additional control for structure. A measure of the rate of growth of GDP p.c. in the area of each country outside the major FURs is included as a control for national institutional, policy and other factors which may have led to countries having had country-specific differences in their growth rates over the period. The variable should also effectively control for national differences in the incidence of the economic cycle. In the models in which population growth is the dependent variable a comparable variable - the rate of natural increase of population in the territory of the country outside its major FURs - is used.

Although national dummies have been the way in which this problem has frequently been handled in the literature, it seems more elegant and powerful to use the continuous variable employed here. It is also consistent with our belief that our observations - all the large city-regions of the EU of 12 represent in a statistical sense a homogeneous population. Moreover, as is shown in Cheshire and Magrini (2006b), the non-FUR growth variable performs very much better econometrically than national dummies. A further point of interest is that it eliminates the significance of any measure of the initial level of GDP p.c. Previous work has shown that both the significance and even sign of this commonly used variable were highly dependent on 
model specification (Cheshire and Carbonaro, 1996) and this confirms that result. It suggests that there is more variance in FUR growth rates across countries than within them and that the initial level of GDP p.c. acts in large measure as a national dummy. This finding is one factor underlying our scepticism with respect to the many estimates of so-called $\beta$-convergence following Barro (1990) and Barro and Sala-i-Martin (1991; 1992; 1995). All the results of models which included the initial level of per capita income were unsatisfactory, with highly unstable co-efficient estimates associated with the variable and problems of collinearity.

\section{Table 1 about here}

\section{3a. Results of modelling urban growth rates: population growth}

We start with a brief summary of the results from modelling population growth in the FURs of the EU of 12 between 1980 and 2000 as reported in Cheshire and Magrini (2006a). Because the natural rate of increase of population for the area of the country outside its major FURs is included as an independent variable, we are in effect estimating a quasi-net migration model. Table 2a shows the results for a base model with no climate variables in column 1 and two of the best performing models in columns 2 and 3 . In all models, a quadratic form for the climate variables performs best. As well as the standard controls two other variables were included. The first is an 'interaction' variable designed to measure localised employment opportunity differentials in the early part of the period. This is formulated on the basis that changes in commuting patterns are a potential source of spatial adjustment where there are densely packed FURs. Changes in commuting patterns induced by local differential employment opportunities at the start of the period are assumed to be likely to be at least in part converted to actual migration gain later. The variable is measured as the sum of all the changes in employment in a FUR and all surrounding FURs within 100 minutes travel time between 1979 and 1991 discounted by travel time distance (so the impact on the value of the variable of a given change in employment declines as the 
distance between FURs increases and falls to zero if the distance exceeds 100 minutes). The second is the 'Integration Gain' variable designed to measure the systematic spatial incidence of economic gains from EU integration. The rationale for this is explained in Cheshire and Magrini (2000) but the variable measures the change in predicted economic potential for each FUR resulting from the integration of the EU of 12 (including lower transport costs). The values of the variable are calculated from Clark et al. (1969) supplemented with the calculations of Keeble et al. (1988).

Climate variables were formulated in two ways. The first was for each FUR relative to the mean value for the EU of 12 as a whole: the second was relative to the mean for the country. Variables relative to EU values proved wholly non-significant but when formulated relative to country means were strongly significance and also had a substantial impact in absolute terms. The linear estimates for each independent climate variable provided a simple guide to the overall impact of that aspect of climate on population growth. They showed that more cloud cover and wetness had a negative impact on growth and a warmer and drier climate had a positive impact. Model 1 is the 'base' model: Models 2 and 3 include combinations of climate variables: frost frequency, maximum temperature and wet day frequency - all calculated as ratios of the country values. It will be seen that these models appear to perform well and provide striking evidence that climatic differences were strongly and significantly associated with differential rates of urban population growth. It was found, for example, that these climate variables performed in a similar way, but statistically more significantly to, simple geographic variables measuring how far south or west FURs were relative to national datum points. Since the climate variables (and indeed the geographic ones) are only significant when measured as differences within countries there is no evidence to suggest that differences in climate across the EU as a whole were relevant: rather the results suggest that in the last decades of the 20th Century population in all countries in the EU of 12 were attracted by, and able on the margin to choose to live in places in their countries which had more agreeable 
climates. This is not inconsistent with a degree of international population mobility associated with climatic differences. But it suggests that in so far as people did make such moves, they selected the country first and then, in choosing locations within countries, chose cities with better weather.

\section{Table 2a about here}

Table $2 \mathrm{~b}$ reports the critical results of a series of diagnostics tests for specification and spatial dependence for the same three models. Full results are available from the authors but these show the important results. As is well known the major problem in testing for problems of spatial dependence is the choice of measures of 'proximity'. Past experience (see, for example, Cheshire and Magrini, 2000) had shown that the most sensitive measure of distance when analysing growth differences between European FURs was the inverse of time distance between pairs of FURs (measured as transit time by road including any ferry crossings and using the standard commercial software for road freight). In the present case, we tested for both the inverse of time distance and the inverse of time distance squared and, in addition, experimented with an added time distance for all FURs separated by a national border. 'Time' effects tested for national borders varied from zero to 120 minutes. We found that the greatest sensitivity in the tests for spatial dependence was achieved if the time cost of a national border was set at 120 minutes. In addition, the most sensitive measure of total distance was if the distance between each pair of FURs was represented as the inverse of time distance (including the 120 minutes for a national border) squared.

The diagnostic tests suggest that there are no problems of either heteroskedasticity or non-normality of errors. The value of the multicollinearity condition number is relatively high in the models in which climate variables are included in quadratic form but since the parameter estimates are stable and the functional form (effectively suggesting that it is asymptotic to an upper value) seems sensible, we are not concerned with this. 
The highest value for the multicollinearity condition was found for Model 3 but this may be because the functional form over the range considered is very close to linear. Of more concern are the results for the tests for spatial dependence. In the models in which climate variables (or 'south within country') were included the LM error test - the most reliable and appropriate suggests no problems of autocorrelation in errors but the results of the LM lag tests (again the most appropriate and reliable) suggest there could be some bias because of the omission of a spatial lag variable (or other specification problem). This seems likely to be a minor problem, however, only showing up as significant at all when distance is represented in the most sensitive form as the inverse of time distance squared including the 120 minute national border effect: and even then, in Model 3, it is close to the $10 \%$ margin of significance.

\section{Table 2 b about here}

Fitting a spatial lag model using maximum likelihood estimation (Cheshire and Magrini, 2006a) produces very similar results to those reported here. As suggested by the tests for spatial dependence, the spatially lagged value of population growth is significant. However, all signs remain appropriate and except for the spatial Integration Gain variable in the 'base' model - all variables are significant at at least $10 \%$. A few variables however, cease to be significant at 5\%. All other variables are significant at $5 \%$ or better, however, and the diagnostics remain reassuring. Perhaps most reassuring of all, and again consistent with the conclusion that problems of spatial dependence are for practical purposes very minor, the coefficient estimates for equivalent models hardly change numerically in the spatially lagged estimate compared to the robust standard errors, OLS estimates reported in Table 2a.

Apart from these variables which are significantly associated with population growth it is worth noting some which are not. Neither the local concentration of university students per employee at the start of the period nor the concentration of R\&D facilities of major companies was significant. Indeed, 
the sign with respect to the $R \& D$ variable was consistently negative and close to significant.

\section{3b. Results of modelling urban growth rates: GDP p.c. growth}

One conclusion from this analysis of urban population growth is that it is unreasonable to apply a full compensating advantages model to the major city regions of the EU. Although the influence of some measures of differential economic opportunities seems to be EU-wide, the effect of climatic differences - the most widely used measure of quality of life differences - are not. Moreover strong national border effects are found when we test for spatial dependence. Not only is migration orders of magnitude less than it is in the US, in the EU it still seems to be significantly confined within national borders. This means that the argument that population movement is the best measure of relative spatial welfare differences (see for example Glaeser et al., 1995) is difficult to sustain in a European context. In turn, this suggests that (differences in) the growth of real incomes is a significant indicator of (changes in) welfare levels across the FURs of the EU. This lends additional importance to understanding sources of differential growth in urban incomes. There is no data available on household disposable incomes across the EU so we have to use real GDP p.c. It is more appropriate to think of these results as investigating sources of productivity rather than income growth, therefore, although the two are likely to be highly correlated.

The results of three models are reported in Table 3a. The first includes only non-spatial control variables. As the tests for spatial dependence (Table 3b) show, this model is subject to significant spatial lag problems and so is open to concerns that it will yield inconsistent parameter estimates for the variables included to test hypotheses about the causal factors in urban economic growth. Rather than attempt to fix these problems by simply introducing a spatial lag, we interpret this result as an example of a wider class of problem: that of omitted variables. We attempt to address the problem, therefore, by extending the logic applied to the population growth models and looking for variables 
which plausibly measure underlying spatial adjustment processes. Model 5 is constructed in this spirit, using what one might think of as 'artisanal' methods - that is including only control variables and variables specifically chosen either to test hypotheses or to account for spatial adjustment processes. Model 6 is a specific model emerging from the automated model selection algorithms employed in PcGets (see Hendry and Krolzig, 2001). The set of variables available to the selection procedure included all variables available, including those relating to climate. All variables are significant and all those in Model 5 have the expected $\operatorname{sign}^{4}$. The automated model selection procedures interestingly include one of the climatic variables (not included in the 'artisanal' modelling process) as well as all those variables included in the artisanal model. This provides evidence that a better climate relative to the national mean was significantly associated with slower growth in GDP pc. This result is discussed below.

As was noted in section 2, the rate of growth of that part of each country outside its major FURs was used as a control - rather than national dummies for basic differences in policy, the incidence of the cycle and other factors. Controls for industrial structure were as employed in Cheshire and Magrini (2000) although the unemployment rate at the start of the period was included as an additional control. Other controls were designed to reflect as far as possible underlying (urban) economic theory and evidence. The $\log$ of population size is included with the expectation that larger cities will have grown faster in terms of GDP p.c. because of productivity gains in larger urban areas (see Costa and Kahn, 2000 for a convincing account of at least one important source of such productivity gains in larger cities). Dynamic agglomeration economies are another possible explanation. Initial population density was included since, allowing for agglomeration economies, cities with higher density will have higher costs of space and greater congestion. A negative relationship is expected. In our judgement, initial population density is likely mainly to reflect differences between FURs in the constraint on urban

\footnotetext{
${ }^{4}$ Models were estimated in Stata using robust standard errors.
} 
land supply produced by land use regulation. Higher density, other things equal, signals a tighter constraint imposed on development. Topography and the inertia of inheritance embodied in the built environment no doubt contribute to differences in densities but probably less than land use policy which varies substantially both across countries and between cities in Europe.

Model 4 (which includes no 'spatial variables') does include variables designed to test significant hypotheses about processes of urban economic growth in Europe. The first pair is straightforward. They are measures of specific, highly skilled, human capital and of relative concentrations of R\&D activity. These are represented as the number of university students per employee over the period 1977 to 1979 in the FUR and as the number of R\&D establishments of Fortune top 500 companies per million population in 1980 . Thus, both are measured right at the start of the period to minimise possible problems of endogeneity.

The last independent variable included in the non-spatial, base model, is designed to test whether there is a relationship between the boundaries of its governments and a FUR's growth rate. With EU integration over the past 20 years there has been an associated development of territorial competition or competition between regions to promote local growth. To the extent that there is an 'output' from such activities, it is local economic growth. Suspending our disbelief in the possible efficacy of local growth policies ${ }^{5}$, any provision of additional local economic growth would be, in effect, the production of a pure local public good. Extra local growth is non-excludable in the sense that if a region's economy grows as a result of local policy, those who did not contribute to the (costs of) the policy cannot be excluded from enjoying its

\footnotetext{
${ }^{5}$ As we stress in Cheshire and Magrini (2006b) we take a very broad view of 'growth promotion policies'. We emphatically do not confine our definition to attempts to lure mobile investors. Such policies probably have a very doubtful potential net benefit. Successful policies might mainly take the form of efficient local public administration which is business friendly, the efficient co-ordination $\mathrm{f}$ infrastructure and economic development and effective education and training policies. Since none of these necessarily cost more than their ineffective counterparts, their strength cannot be measured by local expenditures.
} 
benefits; and it would have a zero opportunity cost in consumption in the sense that if, say, one agent's employment prospects or rents are improved, there would be no reduction in the employment prospects or rents of others. There are, therefore, the usual problems associated with the provision of (local) public goods, including a classic problem of spatial spillovers. Whether or not growth promotion policies are engaged in will be conditioned primarily on the structure of the incentives faced by the economic actors who may attempt to form a public/private consortium or 'growth promotion club'.

It is reasonable to think of any FUR as being made up of one or more administrative units and that a 'club' of administrative units (whether including private sector actors or not) will have to be formed to provide growth promotion policies. It is also reasonable to assume that the largest unit within the FUR - the central unit - will always be a part of such a club, either alone or together with other administrative units, so the territory of a FUR is made up of two potential sets of governmental units: the policy club members and the group of non-participating units.

The expected gross payoff will be a direct function of the additional growth that a given club expects it can generate. Since FURs are defined to be economically self-contained, it is reasonable to assume that the territory their boundaries identify contains any benefits that might be generated by local growth promotion policies. For a given potential growth gain for a FUR (the spatial unit containing the benefits of the growth) the expected payoff for any growth club will fall as the size of the territory they control or represent falls in relation to that of the FUR within the boundaries of which the 'club' is located. This is because the spillover losses to areas of the FUR not represented in the club will increase. Equally, assuming other factors are constant, the expected net payoff would fall as the transactions costs necessarily incurred to form the club increase. Transactions costs will be positively related to the number of relevant potential members and the institutional dominance of the lead actor (which we can assume will be a governmental unit). Thus expected net 
benefits will increase and costs fall as the size of the largest (normally that representing the central unit or urban core) governmental unit increases relative to the size of the FUR. Arguments such as these led Cheshire and Gordon (1996, page 389) to conclude that growth promotion policies would be more likely to appear and be more energetically pursued where "there are a smaller number of public agencies representing the functional economic region, with the boundaries of the highest tier authority approximating to those of the region...".

Applying this analysis it is possible to specify a variable closely reflecting this feature of FURs: the ratio of the total population of the largest (relevant) unit of government representing the FUR to the population of the FUR as a whole. We are implicitly assuming this 'relevant' unit of government will be the unit with the largest population, usually representing the central administrative unit of the FUR, but this is qualified by 'relevant': by which we mean that the governmental unit concerned must have significant powers of action. Even though it might be the largest N.U.T.S. region with a territory overlapping that of the London FUR, for example, one could not define the South East Region as a 'relevant' governmental unit for the London FUR because it had essentially no powers ${ }^{6}$. The rules by which such 'relevant' local government units were identified were established before any models including the variable were estimated so that the variable could be defined blind of the data. These rules are set out in Cheshire and Magrini (2006b).

We call this the policy incentive variable because it is designed to measure the incentive and perhaps the capacity to prosecute policies promoting growth at the FUR level. In identifying the largest 'relevant' unit of government, 'relevant' is defined as a sub-national unit of government with an administrative area encompassing or corresponding to some proportion of the territory of a FUR and which has significant administrative and decisionmaking powers. Since the largest 'relevant' unit was selected, it was also in all

${ }^{6}$ During the period analysed there was a South East Regional Planning Council (SERPLAN) but this was effectively no more than a forum for discussion. 
cases the highest tier of sub-national government relating to the territory of the FUR. Since one criterion was that the unit of government selected should have significant administrative and decision making powers the Level 1 regions were potentially available for selection in European countries with an appropriate regional level of government. In practice, this means that the value of the variable ranged from only about 0.125 to over 2 . We might further hypothesise that if the value of the variable were very high, so that the size of the 'relevant' unit of government considerably exceeded the size of the FUR, then the capacity to generate local growth promoting policies would begin to weaken. This is because the interests of the FUR would begin to be lost in those of the larger unit which might pursue policies favouring rural areas or smaller centres. If this were the case then we would expect to observe a quadratic functional form with a maximum positive impact where the value of the policy incentive variable was between 1 and 2 .

Turning now to the results reported in Tables $3 \mathrm{a}$ and $3 \mathrm{~b}$ we see that all the variables in the core model are significant and have the expected sign except that the co-efficient on the squared term associated with the policy incentive variable is non-significant. Thus, the variable itself is significant but the evidence that the appropriate functional form is quadratic as hypothesised is weak. The adjusted $\mathrm{R}^{2}$, with 121 observations in a cross sectional analysis, is 0.64 . Table $3 \mathrm{~b}$, reporting the results of the diagnostic tests, suggests that there are no problems of non-normality of errors or heteroskedasticity but that if a time distance penalty is included in the distance weights matrix there are significant problems of spatial dependence, most obviously problems of a spatial lag. For the set of models of economic rather than population growth we experimented with a full set of national border time-distance penalties ranging from zero to infinity. Problems of spatial dependence tended to show up most strongly when the penalty imposed for a national border was 600 minutes. 
As noted above we interpret this result as signalling that there is in effect a problem of omitted variables. There are underlying mechanisms of spatial adjustment causing interaction in the growth rates of neighbouring FURs as well as, perhaps, direct spatial effects, so we should not expect the growth behaviour of a FUR to be independent of that of its neighbours. One such factor has already been identified in the context of the analysis of rates of population growth. The process of European interaction has long been argued to differentially favour 'core' regions so the first spatial variable to include is the familiar measure of change in economic potential - or the Integration Gain variable.

A further obvious reason for expecting interaction in the growth rates of neighbouring FURs can be found in the literature on labour market search behaviour. If productivity, wages or job opportunities are relatively improving in one urban area then those who can access those opportunities at the lowest cost - who live nearest - will tend to do so. Migration is expensive but changes in commuting patterns respond to only small differences in opportunities (see, for example, Gordon and Lamont, 1982 or Morrison, 2006). We should expect that if a FUR's growth rate were negatively influenced by a concentration of unemployment in it at the start of the period then a concentration of unemployed in closely surrounding FURs would also have a negative impact. Given the possibility of job search in surrounding labour markets we would expect higher unemployment not to be just localised, moreover, but in densely urbanised regions, we would expect unemployment rates for workers of comparable skill levels to even out between neighbouring FURs. This leads us to introduce as independent variables both the unemployment rate in the FUR itself at the start of the period and the weighted sum of unemployment in all surrounding FURs discounted by distance. Since the search areas of low skilled workers who are disproportionately overrepresented amongst the unemployed are confined geographically, we should expect the impact of unemployment on the economic performance of neighbouring FURs to decline rapidly with distance. Experiment confirmed 
this, showing that the best statistical results were achieved if the cut-off was set at 60 minutes.

Similarly, the literature on the spatial pattern of innovation shows a distance decay effect, with patents tending to be applied more frequently nearer to the location of the patent and innovation rates declining with distance. We should expect the impact of $R \& D$ with respect to innovation to be subject to a distance decay effect, therefore (see for example Audretsch, 1998). This implies that we should expect $R \& D$ in one urban area to have a positive impact on innovation and growth in neighbouring urban areas which would fall as the distance between them increased. Such mechanisms, leading to systematic spatial dependence in the growth rates of FURs, will depend on the costs of commuting and perhaps communication. It, therefore, seems not only most appropriate to formulate these 'spatial' variables so that their impact declines with distance but also to include a specific time-distance penalty for national borders. We in fact experimented with alternative distance decay and national border factors but the best results were obtained using essentially the same formulae as employed to calculate the spatial weights matrix. The impact of unemployment and R\&D on growth performance in neighbouring FURs was assumed to decline with the inverse squared of time-distance and be subject to a 600 minute national border time-distance penalty. As noted above, for unemployment, an upper cut-off of 60 minutes performed best but for $\mathrm{R} \& \mathrm{D}$ the best performing cut-off was found to be 150 minutes.

The fourth 'spatial' variable is the relative concentration of university students in neighbouring FURs at the start of the period, again discounted by distance and with a national border penalty. Here we expect a negative impact on growth in a particular FUR of a stronger relative concentration of university students at the start of the period in neighbouring FURs; and we also expect the distance over which such an effect would be measured to be longer than with unemployment. While a higher stock of unemployed within a tightly clustered set of urban areas should be expected to contribute to lower growth 
in all of them because of the way in which local labour markets work to even out unemployment rates for workers of given skill levels between areas open to commuting ${ }^{7}$, the same is not true of a higher relative stock of university students in surrounding FURs at the start of the period. Here, there is no tendency for their distribution to be evened out by the operation of local labour markets: rather a higher stock within a given FUR at the start of the period represented a resource for future growth. A concentration of workers embodying greater human capital is associated with faster growth over the subsequent period in the FUR in which they are found. Not only should this be expected to increase the growth performance of the FUR (captured in our direct University Student variable) but also the additional growth will increase relative job opportunities and tend to suck in complementary labour, including high human capital labour, from surrounding FURs over the period. Since the commuting range of higher skilled workers is greater, we should expect this effect to be measurable over a longer distance than was the case with unemployment. The best results were obtained if the cut-off was set at 150 minutes to which was again added a 600 minute national border time-distance penalty.

The final 'spatial' variable was a dummy for peripherality. There has been much discussion in the literature of the impact of peripherality. We have already accounted for the impact of European integration via our Integration Gain variable but regions deemed peripheral may have common features (such as lower factor costs for example) and also have tended to be recipients of regional aid from the EU. Although the impact of such aid has been questioned (see, for example, Midelfart and Overman, 2002, or Fratesi and RodriguezPose, 2004) still it is unlikely to have been systematically negative. To avoid subjective judgements about what regions are - or are not - peripheral this variable is formulated simply in terms of time-distance from Brussels; any

\footnotetext{
${ }^{7}$ Although FURs are defined to be as self contained in commuting terms as possible where they are tightly packed (for example in the Ruhr region of Germany) it is virtually zero cost for a worker living on the edge of any FUR to change to commute to the neighbouring FUR(s).
} 
FUR 600 minutes or more from Brussels ignoring national borders is classified as peripheral.

When these variables are added, the model performance improves without significantly changing the parameter estimates associated with the main explanatory variables while the problems of spatial dependence (see Table $3 b$ ) are eliminated. This would seem to be a highly satisfactory result replacing a technical solution (which in this case would have been introducing a spatial lag) with one based on economic mechanisms. Two points about the results reported for Models 5 and particularly 6 should be noted. The first is that although the squared term on the policy incentive variable is still not significant at conventional levels, an F-test shows that neither term should be eliminated: both perform significantly better than either alone. The second point is that when automated methods of model selection are used (see Hendry and Krolzig, 2004) the same set of independent variables is selected plus a quadratic form associated with climate. All else taken into account, there was a statistically significant association between faster economic growth and a FUR having a wetter climate relative to its national average. One should add that the climate variables are highly correlated and if the wetness variable is excluded then the maximum temperature relative to the country is selected and is significant with a negative sign.

At first blush, it may not seem obvious why climate should systematically influence urban economic performance in any causal way and for that reason the climate variables were not included in the 'artisanal' process of model construction. However, drawing on the literature deriving from Roback (1982) and reviewed in Gyourko et al. (1999) there is, in fact, a reasonable argument. A better climate will be capitalised into land prices and traded off by individuals against higher wages. As discussed in section $3 \mathrm{a}$ above, there is strong evidence that national climatic differences are very significant in explaining patterns of population growth and mobility between FURs within countries. This is consistent with a process of sorting between FURs, with 
concentrations of human capital and R\&D facilities being negatively but not significantly associated with population growth, while a drier and warmer climate relative to a country's mean is strongly and significantly associated with population growth. This suggests that there was some selection process going on with people more motivated by quality of life and with lower skills tending to be differentially attracted to cities with a better relative climate. This implies, other things equal, that those more work and skill oriented - together with activities employing such labour - would find costs lower and welfare levels higher in FURs with relatively worse climates. Since this was a dynamic process - the dependent variable was a proxy for net migration over the 20 year period 1980-2000 - it would imply a faster rate of productivity and wage growth in FURs with climates worse than their countries' means. In essence, this is no more than the application of the insight that people who think they are likely to be unemployed anyway might as well live somewhere nice if there is a national system of welfare support.

\section{Table 3a and Table $3 b$ about here}

\section{The contrasts and similarities: conclusions}

The contrasts and similarities in these two sets of models not only reveal some interesting differences in the drivers of population compared to real GDP per capita growth but also suggests some insights into the underlying patterns of, and constraints on, urban change in the EU of 12. Cities (as FURs) with greater attraction to population and greater productivity growth have some important structural characteristics in common. They share a common inheritance in terms of the old resource based industries of coal mining and port activity: these were underrepresented in the fast growing cities. Similarly, the faster growing cities were in wider regions with significant but not excessive agricultural employment (the very high proportions of agricultural employment in 1975 were found only in a few regions which still had a substantial, undercapitalised peasant population). Moreover, they had two related structural factors in common also: at the start of the period, there was a 
lower representation of industrial activity (favouring population growth) or lower relative unemployment (favouring economic growth). Finally there was one more EU-wide economic influence the more dynamic cities shared: they tended to be the systematic beneficiaries of the effects of European integration as measured by the change in economic potential associated with the formation and enlargement of the EU and falling transport costs. These were all EU-wide influences on urban growth of both population and GDP pc. However, of these only really the impact of European integration can be thought of as a European-wide factor. The other factors are common but could all be working within a national context. Having a coal mining inheritance, for example, was a negative for both economic and population growth but that is consistent with it simply being that in the last two decades of the 20th Century coal mining was declining in all of the old established areas and left behind a set of skills and an environment unattractive to migrants and new economic activity everywhere.

A set of equally significant factors differs. We find that a relatively better climate within, but only within, countries was statistically the single most significant factor associated with differential population growth. Quality of life differences were important in making cities more or less attractive to people but only quality of life differences between cities within the same country. On the other hand, stronger economic growth was significantly associated with a city having a worse climate relative to the rest of its country once all other factors had been allowed for. As argued above, this finding is consistent with the quality of life model and a process of sorting of population between locations (within countries) meaning that less work oriented/less highly skilled people seemed to be choosing a better climate (driving up property prices) relative to employment opportunities. One may even be able to see the impact of this in the different role of a city's share of industrial employment at the start of the period compared to unemployment. A higher level of unemployment was found to be associated with slower economic growth; and higher unemployment is associated with worse employment prospects and a 
less skilled labour force on average. However, although an initial relative specialisation in industry is correlated positively with higher unemployment, the variable appearing as significant in the population growth models is industrial specialisation. One should put this finding together with findings from the housing market hedonic literature (for example Cheshire and Sheppard, 1995) or the literature on population and employment decentralisation (for example, Thurston and Yezer, 1994) which concludes that the presence of industry is an environmental 'bad' which people pay a premium to have less of in their neighbourhoods or move away from. Looked at in this light then one can see that less industry in a city might have attracted mobile population while more unemployment would be less significant. At the same time, more unemployment would be a negative factor in terms of growth of per capita incomes or productivity while more industry was neutral.

We also find that a concentration of potentially highly productive workers (university students) was favourable to productivity growth but not significant in the context of population growth and a concentration of R\&D activity was also significantly associated with productivity growth but, if anything, negatively associated with population growth. This latter finding is again consistent with a process of sorting of more highly skilled and work oriented people concentrating in higher income and growth cities while less skilled or work orientated concentrated in cheaper and 'nice' cities. We also find that having a government structure more favourable to promoting local economic growth helped a city's growth performance in economic terms but had no impact on its population growth.

When we compare patterns of spatial interaction and spatial dependence we find revealing features in common. The models do not work in identical ways - the details of the mechanisms of spatial interaction differ - but the fundamental patterns are similar. We can identify economic mechanisms, chiefly relating to search patterns in local labour markets and to differences in the costs of changing commuting patterns compared to migration, which 
produce systematic interaction in growth of both population and productivity. In the case of productivity growth, we can also identify interaction mechanisms resulting from the tendency to apply innovations locally. Europe seems to be composed of city-states but these are not isolated city-states: where they are densely packed, they locally interact. They still exist largely within national urban systems, however, so even discounting for the low incidence of population mobility in Europe compared to the US, we should not expect to observe a full spatial equilibrium across the whole set of city-regions in the EU. Not only do national borders still represent substantial barriers to spatial interaction - apparently the equivalent of a day's travel time - but quality of life differences, although important determinants of the attractiveness of a city to mobile population, still seem to be confined in their influence to their own national territories. 


\section{References}

Barro, R.J. (1990), “Government Spending in a Simple Model of Endogenous Growth”, Journal of Political Economy, 98, S103-S125.

Barro, R.J. and X. Sala-i-Martin (1991), "Convergence across States and Regions", Brooking Papers on Economic Activity, 1, 107-182.

Barro, R.J. and X. Sala-i-Martin (1992), “Convergence” Journal of Political Economy, 100 (2), 223-251.

Barro, R.J. and X. Sala-i-Martin (1995), Economic Growth, New York: McGraw-Hill.

Cheshire, P.C. and D. G. Hay (1989), Urban Problems in Western Europe: An Economic Analysis, London: Unwin Hyman.

Cheshire, P.C. and G. Carbonaro (1996), "European Urban Economic Growth: Testing Theory and Policy Prescriptions”, Urban Studies, 33 (7), 11111128.

Cheshire, P.C. and I.R. Gordon (1996), "Territorial Competition and the Logic of Collective (In)action", International Journal of Urban and Regional Research, 20, 383-399.

Cheshire, P.C. and S. Magrini (2000), "Endogenous Processes in European Regional Growth: Implications for Convergence and Policy”, Growth and Change, 32 (4), 455-479.

Cheshire, P.C. and S. Magrini (2006a), "Population Growth in European Cities: Weather Matters - But Only Nationally", Regional Studies, 40 (1), 23-37.

Cheshire, P.C. and S. Magrini (2006b), "European Urban Growth: Now for Some Problems of Spaceless and Weightless Econometrics", DSE Working Paper No. 23/2006, Deparment of Economics, University of Venice.

Cheshire P. and S. Sheppard (1995), "On the Price of Land and the Value of Amenities", Economica, 62 (246), 247-267

Clark, C., F. Wilson, and J. Bradley (1969), "Industrial Location and Economic Potential in Western Europe', Regional Studies, 3, 197-212. 
Costa, D.L. and M.E. Kahn (2000), "Power Couples: Changes in the Locational Choice of the College Educated, 1940-1990", Quarterly Journal of Economics, 115 (4), 1287-1315.

Fratesi, U. and A. Rodriguez-Pose (2004), "Between Development and Social Policies: The Impact of European Structural Funds in Objective 1 Regions", Regional Studies, 38 (1), 97-113.

Fujita, M., P. Krugman and A. Venables (1999), The Spatial Economy, Cambridge MA: MIT Press.

Glaeser, E.L., J.A.Scheinkman and A. Shleifer (1995), "Economic Growth in a Cross-Section of Cities", Journal of Monetary Economics, 36, 117143.

Gordon, I. and D. Lamont (1982), “A Model of Labour-Market Interdependencies in the London Region”, Environment and Planning A, 14, 238-264.

Gyourko, J., M. Kahn and J. Tracy (1999), "Quality of Life and Environmental Comparisons" in P.C. Cheshire and E. Mills (Eds.) Handbook of Regional and Urban Economics, Vol. 3: Applied Urban Economics, Amsterdam: North Holland.

Hendry D.F. and H.-M. Krolzig (2001), Automated Econometric Model Selection Using PcGets, Timberlake Consultants.

Hendry D.F. and H.-M. Krolzig (2004), "We Ran One Regression”, Oxford Bulletin of Economics and Statistics, 66 (5), 799-810.

Keeble, D., J. Offord and S. Walker (1988), Peripheral Regions in a Community of Twelve Member States, Luxembourg: Office of Official Publications.

Magrini, S. (1997), "Spatial Concentration in Research and Regional Income Disparities in a Decentralised Model of Endogenous Growth", Research Paper in Environmental and Spatial Analysis No. 43, London School of Economics.

Magrini, S. (1998), Modelling Regional Economic Growth: The Role of Human Capital and Innovation, Ph.D. Thesis, London School of Economics. 
Midelfart, K.H and H.G. Overman (2002), "Delocation and European Integration: Is European Structural Spending Justified?", Economic Policy, 35, 321-359.

Morrison, P. S. (2005), “Unemployment and Urban Labour Markets', Urban Studies, 42 (12), 2261-2288.

Oates, W.E. (1999), “An Essay on Fiscal Federalism”, Journal of Economic Literature, XXXVII, 1120-49.

Roback, J. (1982), "Wages, Rents, and the Quality of Life', Journal of Political Economy, 90, 1257-1278.

Rodriguez-Pose, A. (1998), The Dynamics of Regional Growth in Europe: social and political factors, Oxford: Clarendon Press.

Romer, P. (1990), “Endogenous Technological Change”, Journal of Political Economy, 98, S71-S102.

Thurston L. and A.M.J. Yezer (1994), "Causality in the Suburbanization of Population and Employment", Journal of Urban Economics, 35 (1), 105-118. 
Table 1: $\quad$ Variable Definitions

\begin{tabular}{|c|c|c|}
\hline No & Variable Name & Description \\
\hline & Constant & \\
\hline 1 & Ln Population & Natural log of population in 1979 \\
\hline 2 & Population density & Density of population in FUR in 1979 \\
\hline 3 & Industrial Emp. 1975 & $\%$ of labour force in industry in surrounding NUTS 2 region 1975 \\
\hline 4 & Coalfield: core & A dummy $=1$ if the core of the FUR is located within a coalfield \\
\hline 5 & Coalfield: hinterland & A dummy $=1$ if the hinterland of the FUR is located in a coalfield \\
\hline 6 & Port size $1969^{*}$ & Volume of port trade in 1969 in tons \\
\hline 7 & Agric Emp.1975* & $\%$ of labour force in agriculture in surrounding NUTS 2 region 1975 \\
\hline 8 & Unemployment 1977/81* & Mean FUR unemployment rate 1977 to 1981 \\
\hline 9 & $\begin{array}{l}\text { Nat Ex-FUR GDP Growth '79- } \\
\text { '93 }\end{array}$ & $\begin{array}{l}\text { Annualised rate of growth of GDP p.c. in the territory of each country } \\
\text { outside major FURs between 1978/80 and 1992/94 }\end{array}$ \\
\hline 10 & Nat Ex-FUR Pop Grow '80-'00 & $\begin{array}{l}\text { Annualised rate of growth of population in territory of country outside } \\
\text { major FURs between } 1980 \text { and } 2000\end{array}$ \\
\hline 11 & Policy Incentive* & $\begin{array}{l}\text { Ratio of FUR population to that of the largest governmental unit } \\
\text { associated with the FUR (1981): see below for details. }\end{array}$ \\
\hline 12 & $\begin{array}{l}\text { University Students emp. ratio } \\
\text { 1977/78/79* }\end{array}$ & Ratio of university students $1977-78$ to total FUR employment 1979 \\
\hline 13 & $\begin{array}{l}\text { R\&D Facilities per million } \\
\text { population* }\end{array}$ & $\begin{array}{l}\text { R\&D laboratories of Fortune top } 500 \text { companies per million population } \\
1980\end{array}$ \\
\hline 14 & South within Country & $\begin{array}{l}\text { Distance south of centre of FUR from national capital city (Amsterdam } \\
\text { taken as capital of Netherlands; Bonn of Germany) }\end{array}$ \\
\hline 15 & West within Country & $\begin{array}{l}\text { Distance west of centre of FUR from national capital city (Amsterdam } \\
\text { taken as capital of Netherlands; Bonn of Germany) }\end{array}$ \\
\hline 16 & South within EU & Distance south of centre of FUR from Bruxelles/Brussel \\
\hline 17 & West within EU & Distance west of centre of FUR from Bruxelles/Brussel \\
\hline 18 & Frost frequency* & $\begin{array}{l}\text { Ratio of frequency of days with frost between FUR and national } \\
\text { average (1970s and 1980s) }\end{array}$ \\
\hline 19 & Wet days* & $\begin{array}{l}\text { Ratio of wet day frequency between FUR and national average (1970s } \\
\text { and 1980s) }\end{array}$ \\
\hline 20 & Maximum temperature* & $\begin{array}{l}\text { Ratio of maximum temperature between FUR and national average } \\
(1970 \text { s and } 1980 \text { s) }\end{array}$ \\
\hline 21 & Integration Gain* & $\begin{array}{l}\text { Change in economic potential for FUR resulting from pre-Treaty of } \\
\text { Rome EEC to post enlargement EU with reduced transport costs }\end{array}$ \\
\hline 22 & Peripherality dummy & Dummy $=1$ if FUR more than 10 hours time distance from Brussels \\
\hline 23 & $\begin{array}{l}\text { University Student density } \\
\text { employment }\end{array}$ & $\begin{array}{l}\text { Sum of university students per } 1000 \text { employees in all FURs within } 150 \\
\text { minutes travel time discounted by distance with } 600 \text { time penalty } \\
\text { added for national borders }\end{array}$ \\
\hline 24 & $\begin{array}{l}\text { R\&D Facilities density } \\
\text { population }\end{array}$ & $\begin{array}{l}\text { Sum of R\&D Facilities per million population in all FURs within } 150 \\
\text { minutes travel time discounted by distance with } 600 \text { time penalty for } \\
\text { national borders }\end{array}$ \\
\hline 25 & Unemployment 1977/81 density & $\begin{array}{l}\text { Sum of differences between the unemployment rate (average between } \\
1977 \text { and 1981) of a FUR and the rates in neighbouring FURs up to } 60 \\
\text { min away discounted by time-distance with a } 600 \text { minute time-distance } \\
\text { border penalty. }\end{array}$ \\
\hline 26 & Interaction '79-'91 & $\begin{array}{l}\text { Sum of the differences in the growth rate of employment in the FUR } \\
\text { and in all FURs within } 100 \text { minutes travelling time discounted by } \\
\text { distance over the period 1979-1991 }\end{array}$ \\
\hline
\end{tabular}


Table 2a: Dependent Variable: FUR Population Growth Rate 1980 to 2000; Selected Models

\begin{tabular}{|c|c|c|c|}
\hline Model & 'Base' Model 1 & Model 2 & Model 3 \\
\hline R-squared & 0.5180 & 0.6326 & 0.6405 \\
\hline Agric Emp.’75 & 0.0004102 & 0.0004266 & 0.0004079 \\
\hline std. err. & 0.0000974 & 0.0000987 & 0.0000923 \\
\hline $\mathrm{t}$ & 4.21 & 4.32 & 4.42 \\
\hline Agric Emp.' $75^{2}$ & -0.0000094 & -0.00000826 & -0.00000753 \\
\hline std. err. & 0.0000026 & 0.00000249 & 0.00000246 \\
\hline $\mathrm{t}$ & -3.61 & -3.31 & -3.06 \\
\hline Industrial Emp.' 75 & -0.0001693 & -0.0001457 & -0.0001213 \\
\hline std. err. & 0.0000416 & 0.0000393 & 0.0000341 \\
\hline $\mathrm{t}$ & -4.07 & -3.71 & -3.55 \\
\hline Coalfield: core & -0.0021143 & -0.001655 & -0.001812 \\
\hline std. err. & 0.0008684 & 0.0007881 & 0.000748 \\
\hline $\mathrm{t}$ & -2.43 & -2.10 & -2.42 \\
\hline Coalfield: hint'land & -0.0020548 & -0.001682 & -0.0018028 \\
\hline std. err. & 0.0008282 & 0.0007934 & 0.0007607 \\
\hline $\mathrm{t}$ & -2.48 & -2.12 & -2.37 \\
\hline Port size '69 & -0.0007278 & -0.0006274 & -0.0006521 \\
\hline std. err. & 0.0002844 & 0.0002422 & 0.0002469 \\
\hline $\mathrm{t}$ & -2.56 & -2.59 & -2.64 \\
\hline Port size ${ }^{\prime} 69^{2}$ & 0.0000366 & 0.0000294 & 0.0000315 \\
\hline std. err. & 0.0000146 & 0.0000123 & 0.0000124 \\
\hline $\mathrm{t}$ & 2.51 & 2.39 & 2.55 \\
\hline Nat Ex-FUR Pop Grow '80-'00 & 0.4417852 & 0.5536141 & 0.4710524 \\
\hline std. err. & 0.1117606 & 0.1127851 & 0.1075922 \\
\hline $\mathrm{t}$ & 3.95 & 4.91 & 4.38 \\
\hline Integration Gain ${ }^{2}$ & 0.0011278 & 0.0020954 & 0.0020679 \\
\hline std. err. & 0.0004542 & 0.0004612 & 0.0004593 \\
\hline $\mathrm{t}$ & 2.48 & 4.54 & 4.50 \\
\hline Interaction '79-'91 & 0.0440806 & 0.0532723 & 0.0519908 \\
\hline std. err. & 0.0209222 & 0.0197226 & 0.0190658 \\
\hline $\mathrm{t}$ & 2.11 & 2.70 & 2.73 \\
\hline Frost frequency ratio : country & & -0.0039281 & \\
\hline std. err. & & 0.001571 & \\
\hline $\mathrm{t}$ & & -2.50 & \\
\hline Frost frequency ratio ${ }^{2}$ : country & & 0.0020628 & \\
\hline std. err. & & 0.0006133 & \\
\hline $\mathrm{t}$ & & 3.36 & \\
\hline Maximum temperature ratio : country & & & -0.0752656 \\
\hline std. err. & & & 0.0322676 \\
\hline $\mathrm{t}$ & & & -2.33 \\
\hline Maximum temperature ratio ${ }^{2}$ : country & & & 0.0379645 \\
\hline std. err. & & & 0.0151008 \\
\hline $\mathrm{t}$ & & & 2.51 \\
\hline Wet day frequency ratio : country & & -0.0247 & -0.0202854 \\
\hline std. err. & & 0.0065655 & 0.0056615 \\
\hline $\mathrm{t}$ & & -3.76 & -3.58 \\
\hline Wet day frequency ratio ${ }^{2}$ : country & & 0.008621 & 0.0069708 \\
\hline std. err. & & 0.0030658 & 0.0029409 \\
\hline $\mathrm{t}$ & & 2.81 & 2.37 \\
\hline
\end{tabular}

Notes: All parameter estimates significant at $5 \%$ or better. 
Table 2b: Diagnostics for Population Growth - Models 1, 2 and 3

\begin{tabular}{|c|c|c|c|c|c|c|c|c|c|}
\hline & \multicolumn{3}{|c|}{ 'Base' Model 1} & \multicolumn{3}{|c|}{ Model 2} & \multicolumn{3}{|c|}{ Model 3} \\
\hline $\mathrm{R}^{2}$-adj & \multicolumn{3}{|c|}{0.4741} & \multicolumn{3}{|c|}{0.5841} & \multicolumn{3}{|c|}{0.5930} \\
\hline LogLikelihood & \multicolumn{3}{|c|}{550.3160} & \multicolumn{3}{|c|}{566.7440} & \multicolumn{3}{|c|}{568.063} \\
\hline F-test & \multicolumn{3}{|c|}{11.8200} & \multicolumn{3}{|c|}{13.0361} & \multicolumn{3}{|c|}{13.4905} \\
\hline F-test (prob) & \multicolumn{3}{|c|}{0.0000} & \multicolumn{3}{|c|}{0.0000} & \multicolumn{3}{|c|}{0.0000} \\
\hline Regression Diagnostics & \multirow{3}{*}{\multicolumn{3}{|c|}{19.7911}} & \multirow{3}{*}{\multicolumn{3}{|c|}{143.0190}} & \multirow{3}{*}{\multicolumn{3}{|c|}{487.77}} \\
\hline Multicollinearity Condition Number & & & & & & & & & \\
\hline Test On Normality Of Errors & & & & & & & & & \\
\hline Test & DF & Value & Prob & $\mathrm{DF}$ & Value & Prob & & & \\
\hline Jarque-Bera & 2 & 4.4466 & 0.1083 & 2 & 2.4107 & 0.2996 & 2 & 1.3645 & 0.5055 \\
\hline \multicolumn{10}{|l|}{ Diagnostics For Heteroskedasticity (random coeff.) } \\
\hline Test & $\mathrm{DF}$ & Value & Prob & $\mathrm{DF}$ & Value & Prob & $\mathrm{DF}$ & Value & Prob \\
\hline Breusch-Pagan & 10 & 9.4059 & 0.4941 & 14 & 15.3892 & 0.3521 & 14 & 15.7706 & 0.3276 \\
\hline \multicolumn{10}{|l|}{ Diagnostics For Spatial Dependence } \\
\hline Test & $\mathrm{MI} / \mathrm{DF}$ & Value & Prob & $\mathrm{MI} / \mathrm{DF}$ & Value & Prob & $\mathrm{MI} / \mathrm{DF}$ & Value & Prob \\
\hline & \multicolumn{9}{|c|}{ For Weight Matrix 120 mins borders +Inverse time distance } \\
\hline Moran’s I (Error) & 0.0245 & 3.1722 & 0.0015 & 0.0175 & 2.9603 & 0.0031 & 0.0124 & 2.5297 & 0.0114 \\
\hline Lagrange Multiplier (Error) & 1 & 1.4695 & 0.2254 & 1 & 0.7497 & 0.3866 & 1 & 0.3764 & 0.5395 \\
\hline Lagrange Multiplier (Lag) & 1 & 3.1892 & 0.0741 & 1 & 2.6616 & 0.1028 & 1 & 1.6872 & 0.1940 \\
\hline & \multicolumn{9}{|c|}{ For Weight Matrix 120 mins borders +Inverse time distance squared } \\
\hline Moran’s I (Error) & 0.1248 & 3.2825 & 0.0010 & 0.0797 & 2.5592 & 0.0105 & 0.0726 & 2.3999 & 0.0164 \\
\hline Lagrange Multiplier (Error) & 1 & 5.7734 & 0.0163 & 1 & 2.3529 & 0.1250 & 1 & 1.9511 & 0.1625 \\
\hline Lagrange Multiplier (Lag) & 1 & 8.8033 & 0.0030 & 1 & 4.1270 & 0.0422 & 1 & 2.8366 & 0.0921 \\
\hline
\end{tabular}

Notes: Italics indicates significant at $10 \%$ and Bold at 5\%. 
Table 3a: Dependent Variable Annualised Rate of Growth of GDP p.c. Mean 1978/80 to Mean 1992/4

\begin{tabular}{|c|c|c|c|}
\hline $\mathrm{R}^{2}$ & $\begin{array}{c}\text { Model } 4 \\
06785\end{array}$ & & Model 6 \\
\hline Adjusted $\mathrm{R}^{2}$ & $\begin{array}{l}0.6785 \\
0.6372\end{array}$ & $\begin{array}{l}0.7555 \\
0.7095\end{array}$ & $\begin{array}{l}0.7719 \\
0.7235\end{array}$ \\
\hline AIC & -10.8686 & -11.0440 & -10.9797 \\
\hline LIK & -671.552 & -688.488 & 692.681 \\
\hline Observations & 121 & 121 & 121 \\
\hline Constant & -0.03200 & -0.0262573 & -0.03772 \\
\hline s.e. & 0.00937 & 0.009193 & 0.01004 \\
\hline Nat Ex-FUR GDP Growth '79-'93 & 0.94416 & 0.902537 & 0.85222 \\
\hline s.e. & 0.10238 & 0.097571 & 0.09720 \\
\hline Coalfield - core & -0.00621 & -0.005213 & -0.00524 \\
\hline s.e. & 0.00120 & 0.001287 & 0.00128 \\
\hline Coalfield - hinterland & -0.00418 & -0.003176 & -0.00327 \\
\hline s.e. & 0.00160 & 0.001526 & 0.00150 \\
\hline Port Size & -0.00147 & -0.000922 & -0.00096 \\
\hline s.e. & 0.00040 & 0.000379 & 0.00037 \\
\hline Port Size squared & 0.00008 & $0.000045^{*}$ & 0.000047 \\
\hline s.e. & 0.00003 & 0.000024 & 0.000023 \\
\hline Agricultural Employment & 0.00051 & 0.000484 & 0.00034 \\
\hline s.e. & 0.00016 & 0.000159 & 0.00016 \\
\hline Agricultural Employment squared & -0.000013 & -0.000012 & -0.000010 \\
\hline s.e. & 0.000004 & 0.000004 & 0.000004 \\
\hline Unemployment Rate & & -0.00031 & -0.00035 \\
\hline s.e. & & 0.000136 & 0.00014 \\
\hline Population Size & 0.002118 & 0.001611 & 0.001496 \\
\hline s.e. & 0.000600 & 0.000557 & 0.00055 \\
\hline Population Density & -0.0000015 & -0.0000013 & -0.0000013 \\
\hline s.e. & 0.0000007 & 0.0000006 & 0.0000006 \\
\hline University Students & 0.0000309 & 0.000031 & 0.0000259 \\
\hline s.e. & 0.0000116 & 0.000011 & 0.0000104 \\
\hline R\&D Facilities & 0.000808 & 0.000845 & 0.00079 \\
\hline s.e. & 0.000285 & 0.000275 & 0.00027 \\
\hline Policy Incentive & 0.007500 & $0.008562^{\mathrm{a}}$ & $0.00770^{\mathrm{a}}$ \\
\hline s.e. & 0.00335 & 0.003455 & 0.00253 \\
\hline Policy Incentive squared & -0.002089 & $-0.002647^{* a}$ & $-0.00253^{\mathrm{a}}$ \\
\hline s.e. & 0.001580 & 0.001554 & 0.00153 \\
\hline Wet days & & & 0.03834 \\
\hline & & & 0.01450 \\
\hline Wet days squared & & & -0.01928 \\
\hline & & & 0.00725 \\
\hline Integration Gain & & 0.005162 & 0.00435 \\
\hline s.e. & & 0.001430 & 0.00149 \\
\hline R\&D Facilities Density & & 0.262331 & 0.25088 \\
\hline s.e. & & 0.094307 & 0.09388 \\
\hline Peripherality Dummy & & 0.005411 & 0.00632 \\
\hline s.e. & & 0.001318 & 0.00133 \\
\hline University Students Density & & -0.010527 & -0.01097 \\
\hline s.e. & & 0.003797 & 0.00371 \\
\hline Unemployment Rate Density & & $-0.134403 *$ & $-0.12129^{*}$ \\
\hline s.e. & & 0.069318 & 0.06806 \\
\hline
\end{tabular}

Notes: $4=$ Base model without spatial variables; 5=Artisanal'; 6=PcGets Best Models Italics indicate not significant at 10\%: all variables significant at 5\% except where indicated with an asterisk.

${ }^{a}$ Significant at $10 \%$ only but $\mathrm{F}$ test indicates they should not be excluded as a pair at $5 \%$ level. 
Table 3b: Regression diagnostics for : 4=Base model without spatial variables, 5=Artisanal’ \& 6=PcGets Best Models

\begin{tabular}{|c|c|c|c|c|c|c|c|c|c|}
\hline & \multicolumn{3}{|c|}{ Model 4} & \multicolumn{3}{|c|}{ Model 5} & \multicolumn{3}{|c|}{ Model 6} \\
\hline \multicolumn{10}{|l|}{ Regression Diagnostics } \\
\hline Multicollinearity Condition Number & \multirow{2}{*}{\multicolumn{3}{|c|}{80.62}} & \multirow{2}{*}{\multicolumn{3}{|c|}{100.87}} & \multirow{2}{*}{\multicolumn{3}{|c|}{170.52}} \\
\hline Test On Normality Of Errors & & & & & & & & & \\
\hline Test & $\mathrm{DF}$ & Value & Prob & $\mathrm{DF}$ & Value & Prob & $\mathrm{DF}$ & Value & Prob \\
\hline Jarque-Bera & 2 & 3.3273 & 0.1894 & 2 & 1.2374 & 0.5386 & 2 & 3.1805 & 0.2039 \\
\hline \multicolumn{10}{|c|}{ Diagnostics for Heteroskedasticity (random coeff.) } \\
\hline Test & $\mathrm{DF}$ & Value & Prob & $\mathrm{DF}$ & Value & Prob & $\mathrm{DF}$ & Value & Prob \\
\hline Breusch-Pagan & 13 & 19.3825 & 0.1117 & 19 & 20.8169 & 0.3470 & 21 & 28.6001 & 0.1239 \\
\hline \multicolumn{10}{|l|}{ Diagnostics For Spatial Dependence } \\
\hline \multirow[t]{2}{*}{ Test } & $\mathrm{MI} / \mathrm{DF}$ & Value & Prob & $\mathrm{MI} / \mathrm{DF}$ & Value & Prob & $\mathrm{MI} / \mathrm{DF}$ & Value & Prob \\
\hline & \multicolumn{9}{|c|}{ For Weight Matrix with infinite national border effect + Inverse time distance } \\
\hline Moran’s I (error) & 0.04344 & 1.8729 & 0.0611 & -0.04784 & -0.1457 & 0.8842 & -0.05938 & -0.3514 & 0.7253 \\
\hline Lagrange Multiplier (error) & 1 & 0.9212 & 0.3372 & 1 & 1.1171 & 0.2905 & 1 & 1.7209 & 0.1896 \\
\hline \multirow[t]{2}{*}{ Lagrange Multiplier (lag) } & 1 & 6.6183 & 0.0101 & 1 & 1.4510 & 0.2284 & 1 & 1.5775 & 0.2091 \\
\hline & \multicolumn{9}{|c|}{ For Weight Matrix with infinite national border effect + Inverse time distance squared } \\
\hline Moran’s I (error) & 0.05593 & 1.4068 & 0.1595 & -0.06140 & -0.1916 & 0.8480 & $\mid-0.08193$ & -0.4126 & 0.6799 \\
\hline Lagrange Multiplier (error) & 1 & 0.6996 & 0.4029 & 1 & 0.8432 & 0.3585 & 1 & 1.5016 & 0.2204 \\
\hline \multirow[t]{2}{*}{ Lagrange Multiplier (lag) } & 1 & 7.1177 & 0.0076 & 1 & 1.9795 & 0.1594 & 1 & 1.6855 & 0.1942 \\
\hline & \multicolumn{9}{|c|}{ For Weight Matrix with 600 mins borders + Inverse time distance } \\
\hline Moran’s I (error) & 0.0303 & 2.8693 & 0.0041 & -0.01504 & 0.6940 & 0.4877 & -0.02051 & 0.4639 & 0.6427 \\
\hline Lagrange Multiplier (error) & 1 & 1.5984 & 0.2061 & 1 & 0.3938 & 0.5303 & 1 & 0.7321 & 0.3922 \\
\hline \multirow[t]{2}{*}{ Lagrange Multiplier (lag) } & 1 & 5.8394 & 0.0157 & 1 & 0.9660 & 0.3257 & 1 & 1.1201 & 0.2899 \\
\hline & \multicolumn{9}{|c|}{ For Weight Matrix with 600 mins borders + Inverse time distance squared } \\
\hline Moran’s I (error) & 0.06620 & 1.7888 & 0.0736 & -0.03589 & -0.1484 & 0.8820 & -0.05842 & -0.1759 & 0.8604 \\
\hline Lagrange Multiplier (error) & 1 & 1.3233 & 0.2500 & 1 & 0.3888 & 0.5329 & 1 & 1.0305 & 0.3100 \\
\hline \multirow[t]{2}{*}{ Lagrange Multiplier (lag) } & 1 & 7.1366 & 0.0076 & 1 & 1.5291 & 0.2162 & 1 & 1.2755 & 0.2587 \\
\hline & \multicolumn{9}{|c|}{ For Weight Matrix with 0 mins borders + Inverse time distance } \\
\hline Moran’s I (error) & 0.0143 & 2.3972 & 0.0165 & -0.01538 & 0.4386 & 0.6610 & -0.0159 & 0.5131 & 0.6079 \\
\hline Lagrange Multiplier (error) & 1 & 0.5553 & 0.4561 & 1 & 0.6440 & 0.4223 & 1 & 0.6882 & 0.4068 \\
\hline \multirow[t]{2}{*}{ Lagrange Multiplier (lag) } & 1 & 2.4908 & 0.1145 & 1 & 0.4333 & 0.5104 & 1 & 0.5508 & 0.4580 \\
\hline & \multicolumn{9}{|c|}{ For Weight Matrix with 0 mins borders + Inverse time distance squared } \\
\hline Moran’s I (error) & 0.0573 & 1.7963 & 0.0724 & -0.02911 & 0.1375 & 0.8906 & -0.03337 & 0.1464 & 0.8836 \\
\hline Lagrange Multiplier (error) & 1 & 1.3549 & 0.2444 & 1 & 0.3498 & 0.5542 & 1 & 0.4596 & 0.4978 \\
\hline Lagrange Multiplier (lag) & 1 & 2.8781 & 0.0898 & 1 & 0.1902 & 0.6627 & 1 & 0.1367 & 0.7116 \\
\hline
\end{tabular}

Notes: Results in italics are significant at $10 \%$ level; Results in bold are significant at $5 \%$ level 